УДК 341.1/8

DOI 10.17308/vsu.proc.law.2020.1/2413

\title{
ЮРИДИЧЕСКАЯ СУЩНОСТЬ ЕВРОПЕЙСКОГО СОЮЗА В СОВРЕМЕННЫХ РЕАЛИЯХ
}

\author{
Д. В. Галушко \\ Воронежский государственный университет \\ Поступила в редакцию 23 октября 2019 г.
}

\begin{abstract}
Аннотация: дается характеристика основных подходов, характеризующих юридическую сущность Европейского союза. Высказывается мнение о иелесообразности понимания ЕС как международной организации особого рода (sui generis), сочетающей в себе элеленты классических международных организаций с наднациональныли чертали в ее ббункиионировании. Приводится совреленный процесс прекращения членства Великобритании в ЕC-брексит.

Ключевые слова: Европейский союз, международная организация, региональная интеграиия, членство в ЕC, выход из ЕC, брексит.
\end{abstract}

\begin{abstract}
: the paper describes main approaches that characterize the legal essence of the European Union. The author expresses an opinion on the appropriateness of understanding the EU as an international organization of a special kind (sui generis), which combines elements of classical international organizations with supranational features in its functioning. As a factor confirming this opinion, the current process of termination of UK's membership in the EUBrexit - s given.

Key words: European Union, international organization, regional integration, EU membership, withdrawal from the EU, Brexit.
\end{abstract}

이을 особенностью объединительного процесса в Европе является то, что в начале 50-х гг. XX в. фактически одновременно был дан старт как межправительственной форме интеграции в рамках Совета Европы (впоследствии возникли еще Организация Варшавского договора и Совет экономической взаимопомощи), так и началу наднациональных по

234 своему характеру Европейских сообществ. В настоящее время европейская интеграция в сознании людей ассоциируется, как правило, преимущественно с Европейским союзом. Это связано, прежде всего, с успешным развитием и функционированием ЕС, который сегодня выступает своеобразным образцом для подражания. Несмотря на достаточно успешное развитие ЕС, вопрос о сущности его характеристики до сих пор остается дискуссионным.

Следует выделить три основные концепции, характеризующие сущность Европейского союза и возникшие в процессе развития европейской интеграции. Первая концепция рассматривает Европейский союз

(C) Галушко Д. В., 2020 
как фредерацию (конфедерацию) ${ }^{1}$ (так называемая государственная или «конституционная» концепция). Другая группа ученых характеризует EC как международную региональную организацию (так называемая международно-правовая или «межправительственная» концепция). Третья концепция исходит из того, что Евросоюз является международной организацией особого рода (sui generis) (концепция межгосударственного образования особого характера или «концепция синтеза»)2. Рассмотрим их подробнее.

Идея развития объединенной Европы как федеративного образования неоднократно поднималась в научных и политических дискуссиях ${ }^{3}$. Эта идея определенным образом отразилась и в документах, которые предшествовали созданию ЕС или даже провозглашалась в проектах нормативных актов в качестве одной из целей развития будущей Европы. Стремление развития ЕС по федеративной модели прямо закрепля-

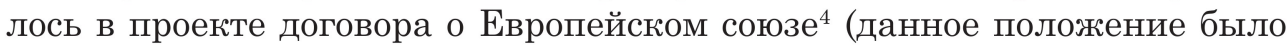
изъято по требованию правительства Великобритании) $)^{5}$. Указанные авторы считают, что ЕС имеет ряд признаков государствоподобного образования федеративного типа. В частности, отмечается, что хотя Союз уже на три четверти отвечает за принятие законодательства в сфере экономики, он находится лишь на начальной стадии федерализации ${ }^{6}$. При этом для доказывания наличия у Европейского союза черт федерации используется теория как кооперативного, так и дуалистического федерализма. К примеру, теория дуалистического федерализма, которая используется в науке конституционного права, основывается на философрской идее о двойном или дуалистическом суверенитете и имеет отношение к тем странам, в которых федеральная власть и власть субъектов фредерации рассматриваются как равноправные и действуют независимо друг от друга в строго определенных для них конституционным правом сферах (конституционная «архитектура» дуалистического федерализма основывается на так называемых "взаимно исключающих полномочиях») 7 . Идея дуалистического федерализма как характеристика правовой и политиче-

${ }^{1}$ Cм., например: Curtin D. The Constitutional Structure of the Union, a Europe of Bits and Pieces // Common Market Law Review. 1993. Vol. 30. P. 17-69.

${ }^{2}$ Европейский союз на пороге XXI века : выбор стратегии развития / под ред. 235 Ю. А. Борко и О. Б. Буториной. М., 2001. С. 449.

${ }^{3}$ См.: Сиджански Д. Федералистское будущее Европы : от Европейского сообщества до Европейского союза. М., 1998 ; Фарукшин M. Х. Сравнительный dеедерализм. Казань, 2003 ; Cartou L. Le Marche commun et le droit public. P., 1959.

${ }^{4}$ См.: Кашкин С. Ю. На пути к европейской конституции : Европейский конвент и перспективы разработки Конституционного договора (Конституции) Европейского союза // Конституционное право : Восточноевропейское обозрение. 2003. № 1 (42). C. 38-41.

${ }^{5}$ Cm.: Cassese S. La Costituzione Europea // Quaderni Costituzionali. 1991. Vol. 11. P. 187-192.

${ }^{6}$ См.: Фарукшин М. Х. Указ. соч. С. 4.

${ }^{7}$ Schutze Robert Dual federalism constitutionalised: the emergence of exclusive competences in the ec legal order / E.L. Rev. 2007. 32(1). P. 3-4. 


\section{Вестник ВГУ. Серия: Право}

ской природы ЕС была развита судебной практикой. Суд ЕС доказывал, основываясь на положениях Договора о Европейском экономическом сообществе ${ }^{8}$, наличие у ЕЭС исключительной компетенции в определенных сфрерах, что и выступало в качестве признака использования теории дуалистического федерализма.

Констатируя наличие федеративных черт в правовой природе Европейского союза, следует также заметить, что в западной науке также существует точка зрения, что ЕС является наднациональной федерацией ${ }^{10}$. Хотя, по нашему мнению, такой подход является попыткой синтезировать черты Европейского союза как федеративного образования и его особые черты как организации нового типа.

В целом на всех этапах европейской интеграции идея развития объединенной Европы именно как федеративного образования неоднократно поднималась в политических и научных дискуссиях, а ее воплощение в жизнь всегда находило мощных лоббистов как на уровне отдельных политиков, общественных организаций, государств ${ }^{11}$, так и институтов Союза. При этом федералистам так и не удалось внести в учредительные договоры хотя бы указание на развитие Союза в направлении федерализма. Однако отказ от фиксации в учредительных договорах термина «федеративный» не означал отказа от развития интеграции в направлении «формирование международно-правовой федерации, которая ранее не была известна человеческой цивилизации» ${ }^{2}$. Приверженцы данной концепции утверждают, что федерализм - это не столько структура, сколько процесс ${ }^{13}$.

Сравнивая Европейский союз с федерацией, прежде всего, хотелось бы подчеркнуть, что федерация - это государство, тогда как Союз не является государством. Следует помнить, что Союз не является суверен- ным образованием; он не имеет своей собственной территории, кроме 이 словно определенной в договорах для их применения; не имеет соб$z$ ственного гражданства, так как ст. 9 Договора о ЕC предусматривает, 후 что гражданином Союза является каждое лицо, имеющее гражданство ㄱ государства-члена. Гражданство Союза дополняет собой национальное гражданство и не подменяет его; источником власти в ЕС является не народ, а правительства государств-членов, которые по своему усмотрению делегируют институтам Союза право осуществления определенных

${ }^{8}$ Opinion 1/75 on a Draft Understanding on a local Cost Standard [1975] / E.C.R. 1355 (ECJ).

9 Cм.: Toth A. G. A Ligal Analysis of Subsiiarity/l Legal Issues of Maastricht Treaty. Ed by D. O’Keeffe \&P.M. Twomey. Wiley Chancery Law, 1994. P. 39.

${ }^{10}$ Cм.: Bogdandy A. Von The European Union as a Supranational Federation: a Conceptual Attempt in the Light of the Amsterdam Treaty // Columbia Journal of European Law. Winter ; L., 2006. P. 127-159.

${ }^{11}$ См.: Горниг Г., Витвицкая О. Право Европейского союза. СПб., 2005. С. 67.

${ }^{12}$ См.: Капустин А. Я. Европейский союз : интеграция и право. М., 2000. С. 60.

${ }^{13}$ См.: Фадеева Т. М. Евросоюз и Российская Федерация : две модели федерализма. М., 2007. С. 10. 
Международное и европейское право

суверенных прав и полномочий, которые необходимы ему для решения задач и в которых заинтересованы страны-участницы (на это обстоятельство прямо указывает принцип наделения компетенцией), поэтому Союз не имеет других полномочий, кроме определенных Договором о ЕС.

Развитие интеграционного процесса за счет роста полномочий Европейского союза в экономической сфере и сфере валютного регулирования, расширение компетенции ЕС в сфере внешней политики и политики безопасности, а также в сфрере внутренних дел и уголовного правосудия также не дает объективных оснований для признания Евросоюза федеративной системой в ее классическом понимании. Можно лишь констатировать, что конструкция, которая объединяет пока еще 28 государств - членов европейского континента, и сегодня по своему устройству остается уникальным образованием, в основе которого сочетаются два разных и одновременно взаимодополняющих типа межгосударственного сотрудничества - международной организации и межгосударственного объединения с комплексом целей и задач и чрезвычайно сложным массивом компетенции и фрнккциональных полномочий. Именно поэтому, определяя формы устройства правовой природы современного Европейского союза, одни ученые видят в нем элементы федерации, другие - конфедерации..

Достаточно популярным в зарубежной и отечественной юридической, особенно политологической, науках является сравнение Европейского союза с конфедерацией ${ }^{14}$, в определенной степени обусловлено существованием многочисленных проектов построения объединенной Европы на конфедеративных началах. Так, Союз рассматривается как международное объединение государств, которые, сохраняя свою независимость, для достижения заранее согласованных целей передают в коллективное распоряжение Союза часть своих суверенных прав, в том числе касающихся внутренних дел. Согласно новейшим научным подходами такое международное объединение государств иногда квалифицируется как современная конфедерация государств ${ }^{15}$.

Однако, несмотря на наличие у ЕС отдельных черт конфедерации, такой вывод следует признать безосновательным, на что неоднократно указывалось многими учеными ${ }^{16}$. Так, очевидно, что в отличие от конфе-

${ }^{14}$ См., например: Hughes Chr. Confederacies. Leicester, 1990. Р. 34 ; Уuaков Н. М. Государство в системе международно-правового регулирования. М., 1997. С. 52-53 ; Чиркин B. E. Федерализм и федеративное государство // Федерализм : теория, институты, отношения (сравнительно-правовое исследование ) / отв. ред. Б. Н. Топорнин. М., 2001. С. 23.

${ }^{15}$ См.: Лазарев Б. М. Федерация или конфедерация // Новый союзный договор : поиск решений / под ред. Б. М. Лазарева. М., 1990. С. 56.

${ }^{16}$ См.: Костенко М. Л., Лавренова Н. В. К вопросу наднациональности и особенностях права ЕС. Европейская интеграция : правовые проблемы // Государство и право. 1994. № 4. С. 109 ; Четвериков А. О. Основные органы Европейского союза (конституционно-правовой аспект) : дис. ... канд. юрид. наук. М., 1999. С. 46-49. 


\section{Вестник ВГУ. Серия: Право}

дерации, Европейский союз - это не временное образование, а организация, которая создана на неограниченное время; Союз функционирует, опираясь на правотворческие и судебные органы, наделенные реальными, а не координационными и консультативными, как в конфедерации, полномочиями; ЕС имеет собственную полноценную правовую, валютную и финансовую системы, что не характерно для конфедерации; не свойственно конфедерации и наличие гражданства (пусть оно и носит субсидиарный характер), прямые выборы населением государств-членов органов власти, прозрачность границ и т. п., как это имеет место быть в рамках Евросоюза.

Концепцию международно-правового характера ЕС отстаивает ряд ученых ${ }^{17}$, при этом некоторые представители науки международного права придерживаются позиции, согласно которой ЕС является международной организацией наднационального, другие - регионального, третьи - субрегионального типа ${ }^{18}$.

Сторонники данной концепции указывают на то, что Европейский союз международную межправительственную организацию, созданную на основе международных договоров, заключенных независимыми государствами, которая обладает собственной международной правосубъектностью. Компетенция Союза определена в его учредительных документах и, как у любой другой международной межправительственной организации, носит функциональный характер. Государства - члены ЕС, присоединившись к Союзу, не перестали существовать в качестве суверенных государств, оставаясь признанными в этом качестве другими субъектами международного права.

Еще одной характеристикой Европейского союза является концепция особого характера ЕC как организации sui generis или концепция межго- сударственного образования особого характера («концепция синтеза») ${ }^{19}$.

${ }^{17}$ Cм.: Schermers H. G. International institutional law. Rockville: Sijthoff \& Noordhoff, 1980. P. 27-33 ; Wyatt and Dashwood's European Union law // A. Arnull [et al] London : Sweet and Maxwell, 2006.

${ }_{18}$ Schermers H. G. International institutional law - Alphen aan den Rijn; Rockville: Sijthoff \& Noordhoff, 1980. P. 27-33 ; Steiner H. J. Transnational legal

238 problems. Materials and Texts. N.Y.: The foundation press, 1994. P. 1082 ; Международное право : учебник / отв. ред. Ю. М. Колосов, В. И. Кузнецов. М., 1999. С. 191 ; Лукашук И. И. Международное право. Особенная часть : учебник. М., 1997. С. 96 ; Ушаков Н. А. Проблемы теории международного права. М., 1988. C. 128 ; Шреплер X.-A. Международные организации : справочник ; пер. с нем. М., 1995. С. 151-167 ; Европейское право : учебник / под общ. ред. Л. М. Энтина. M., 2006.

${ }^{19}$ См.: Капустин А. Я. Международные проблемы природы и действия права Европейского союза : автореф. дис. ... д-ра юрид. наук. М., 2001 ; Топорнин Б. Н. Европейское право : учебник. M., 1998 ; Pescatore P. The Doctrine of Direct Effect : An Infant Disease of Community Law // European Law Review. 1983. Vol. 8. P. 155177 ; Phelan W. What Is Sui Generis About the European Union? Costly International Cooperation in a Self-Contained Regime // International Studies Review. 2012. 14(3). P. 367-385 ; Weatherill S. EC Law. London ; N. Y.: Penguin Books, 1995. 
По мнению некоторых ученых, признание Евросоюза как организации sui generis является самым простым выходом из ситуации. Таким путем идут многие из исследователей евроинтеграции ${ }^{20}$. Тем не менее данная характеристика Союза, на наш взгляд, является наиболее отвечающей современным реалиям развития процессов европейской интеграции. Европейский союз представляет собой уникальное образование, которое формирует свой собственный правопорядок, включающий как международно-правовые, так и внутригосударственные принципы и механизмы. Он выступает в качестве международной организации с элементами наднациональности, созданной в результате интеграционных процессов регионального характера, путем заключения международного договора, в пользу которой государства-члены добровольно передали часть своих суверенных прав, реализация которых возлагается на ее институциональный механизм.

Европейский союз - это, главным образом, межгосударственное объединение очень близкое по своим характеристикам к международным межправительственным организациям, одним из сущностных признаков которых является наличие института членства государств. Членство играет важную роль в определении характера организации и объема ее компетенции и правосубъектности. Членство позволяет международным организациям определять границы своего геополитического, идеологического и правового влияния. Хотя ст. 1 Договора о ЕС указывает на то, что он знаменует собой новый этап в процессе создания более тесного союза между народами Европы, это положение не отменяет межгосударственного характера Союза, поэтому все права и обязанности членов данного международного объединения полагаются на его участников. Однако особенности юридической природы Европейских сообществ/союза привели к тому, что и институт членства в ЕC характеризуется значительным своеобразием, традиционно получившим свое отражение в широко дискутируемых вопросах «расширения ЕС». В настоящее время характер sui generis Европейского союза особенно ярко подтверждается процессом выхода Великобритании из ЕС ${ }^{21}$.

Договор, учреждающий Конституцию для Европы, 2004 г. $^{22}$ впервые закрепил специальную норму о возможности выхода из состава Европейского союза. Несмотря на то что Европейская конституция не вступила в силу, указанные положения вошли в текст Лиссабонского договора 2007 г. ${ }^{23}$, ст. 50 которого устанавливает, что любое государство-член в со-

${ }^{20}$ См.: Четвериков А. О. Основные органы Европейского союза (конституционно-правовой аспект) : дис. ... канд. юрид. наук. М., 1999. С. 41.

${ }^{21}$ Так называемый Brexit (брексит).

${ }^{22}$ Treaty establishing a Constitution for Europe. URL: https://europa.eu/europeanunion/sites/europaeu/files/docs/body/treaty_establishing_a_constitution_for_europe_ en.pdf (дата обращения: 22.10.2019).

${ }^{23}$ Treaty of Lisbon amending the Treaty on European Union and the Treaty establishing the European Community, signed at Lisbon, 13 December 2007 // Official Journal. C 306. 17.12.2007. P. 1-271. 


\section{Вестник ВГУ. Серия: Право}

ответствии со своими конституционными правилами может принять решение о выходе из состава Союза. Государство-член, которое принимает решение о выходе, уведомляет о своем намерении Европейский совет. В свете ориентиров, установленных Европейским советом, Союз проводит переговоры и заключает с данным государством соглашение, которое определяет порядок выхода последнего с учетом основ его будущих взаимоотношений с Союзом. Договоры прекращают применяться к заинтересованному государству со дня вступления в силу соглашения о выходе либо - при отсутствии такого соглашения - через два года с момента уведомления, предусмотренного в параграфе 2, если только Европейский совет с согласия заинтересованного государства-члена единогласно не решит продлить этот срок.

Еще ни одно государство никогда не выходило из ЕС. Первым государством - членом ЕС, которое инициировало данную процедуру, стала Великобритания, в которой 23 июня 2016 г. был проведен референдум по вопросу о возможном выходе из Союза. В результате большинство избирателей высказались за выход страны из $\mathrm{EC}^{24}$. Дата выхода Великобритании несколько раз откладывалась, а условия этого выхода породили серьезные противоречия и кризисные явления как в системе государственного управления Соединенного Королевства, так и в институциональной системе ЕС.

В выходе государства-члена из состава международной организации, в целом, нет ничего особенного. Данная практика включает в себя многочисленные примеры. Однако процесс брексита настолько уникален и чувствителен для обеих сторон, что в современных условиях действительно указывает на особую юридическую сущность Европейского союза как международной организации sui generis, находящейся в самом тесном взаимодействии со своими государствами-членами.

Следует отметить, что современное состояние нормативного урегулирования юридической сущности Европейского союза имеет определенные недостатки. Учредительные договоры ЕC не содержат определения данного объединения, что приводит к выдвижению многочисленных и довольно отличных друг от друга концепций. Тщательный анализ ука240 занных концепций дает основания признать, что хотя каждая из них содержит отдельные черты, которые характеризуют сущность Европейского союза. На наш взгляд, наиболее точно Европейский союз может быть охарактеризован как международная организация особого рода (sui generis). Являясь сложным межгосударственным интеграционным объединением, ЕС сочетает в себе отдельные черты международной межправительственной организации с некоторыми элементами наднациональной организации власти. Особый характер Союза подтверждается современными

${ }^{24}$ Official result of the EU Referendum. URL: http://www.electoralcommission.org. uk/i-am-a/journalist/electoral-commission-media-centre/news-releases-referendums/ official-result-of-the-eu-referendum-is-declared-by-electoral-commission-in-manchester (дата обращения: 22.10.2019). 
тенденциями развития европейской интеграции, в частности процессом прекращения членства Великобритании - брекситом.

Воронежский государственный уни верситет

Галушко Д. В., кандидат юридических наук, доцент кафьедры международного и евразийского права

E-mail: galushkodv@gmail.com

\section{Voronezh State University}

Galushko D. V., Candidate of Legal Sciences, Associate Professor of the International and Eurasian Law Department E-mail: galushkodv@gmail.com 